\title{
Operations Strategy Frameworks in Manufacturing, Services and Product-Service Systems
}

\author{
Cátia Barbosa ${ }^{1}$, Américo Azevedo $^{1,2}$ \\ ${ }^{1}$ Faculty of Engineering, University of Porto \\ ${ }^{2}$ Inesc TEC \\ Porto, Portugal \\ up201409940@fe.up.pt
}

(presented at the 6th IESM Conference, October 2015, Seville, Spain) ${ }^{\circ} \mathrm{I}^{4} \mathrm{e}^{2} 2015$

\begin{abstract}
Many definitions for operations strategy appear in literature. Yet, after analysing some of these important definitions, there were some common denominators: planning and decision-making. It is through correct operations strategy planning and decisions that organizations achieve competitive edge, and for this reason, the subject is of major importance. In this paper we present a review on operations strategy $(O S)$ in manufacturing, services and product-service organizations. Through the literature analysis we found several differences and fewer similarities between OS in manufacturing and services and also the positioning of product-service systems (PSS) OS, comparing to $\mathrm{OS}$ in manufacturing and in services. Our foremost contribution is providing a literature review and an analysis on the content of the OS frameworks.
\end{abstract}

Keywords-framework; manufacturing; operations strategy; product-service systems; services

\section{INTRODUCTION}

Skinner [1] introduced for the first time the concept of an operations strategy (OS). Since then, several definitions for OS appeared in literature. A few examples include the definition by Lowson (2001) [2], Slack and Lewis [3], Van Mieghem [4], or Reid and Sanders [5]. Despite being different, all share common characteristics. There is always the conversion of objectives into action plans, a decision pattern involved in the concept, and all the decisions are medium to long term. Briefly, the purpose of OS is that organizations properly use their competencies, processes and resources to achieve a strong competitive advantage [6], and successfully create value for customers and stakeholders [7]. However, considering Porter's work [8], Enders et al. [9] agree that creating superior value for customers is not sufficient to insure profits; the company must succeed in capturing value. Strategy should be a nonstop learning process as markets are now global and their settings are always changing. It is crucial to have skills to learn to cope with changes $[10,11]$ and even revise the first strategic plan [12]. Thus, all members in an organization have the duty to bind themselves to a continuous learning process and strategy formation [10, 13], being communication a key asset [14]. Constant knowledge building is a competitive advantage [15].

Inside an organization, each division's performance operations management $(\mathrm{OM})$, technology selection, product development, human resources, among others - is affected by OS [16-19]. Given the impact of OS in organizations, some specialize in specific tasks, while others have to be outsourced. This is a means for higher efficiency and cost reduction [20]. It is important that companies tie strategic objectives to operational capabilities, and understand their limits [21, 22].

There are two elements in OS, as stated by Martín-Peña et al. [23]: competitive priorities (CPs) and operations decisions. The first refers to aims the organization pursues and identifies the areas where operations should be outstanding to offer competitive advantage; the second relates to decisions that aid in achieving the operations and corporate goals and can be split into structural and infrastructural. This division was first proposed by Hayes and Wheelwright in 1984 [24].

Van Mieghem [4] proposed a conceptual framework for OS with three crucial components: competencies, resources and processes, as in Fig.1. The framework can build on the market view to define the competencies that operations should develop through proper selection of resources and processes. This refers to a customer driven organization. Indeed, the same framework can be seen from a different perspective, the resource and processes perspective. Here, the resources and products are the strategic building blocks; therefore, it is possible to insure that the value proposition offered to customers will be properly delivered. The second view is resource driven.

The strategy can also be seen as directed or emergent. The first allows the senior management in an organization to build a correct planning for the organization of the internal resources, considering the external environment, and the stakeholders' demands. The second focuses on developing, organizing and using resources to attain operational excellence, competitive advantage, market share and good performance [25].

There has been evolution in the concept of OS due to change in market demands. The OS appeared to respond to highly variable demands from customers [26, 27]. With variety in the OS implementation, companies are challenged to

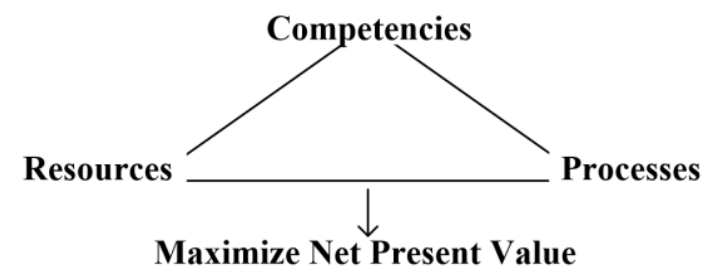

Fig. 1. Operations Strategy Framework (adapted from [4]). 
choose the best methodology. Barnes [28] reviewed practices used in the formation of OS, e.g. interviews, questionnaires, documentation, among others. The author arguments that there is no best alternative when conducting a case study, only a more suitable approach to given settings of the research.

The research presented in this paper covers the topic of OS frameworks. Our study aims to provide an insight on the most important practices in OS in different contexts: manufacturing, services and product service systems (PSS). Therefore, we try to answer two research questions:

RQ1: Is there any difference in OS in manufacturing and services organizations? If so, what distinguishes them?

RQ2: Where does the OS in PSS falls? Does it approach more to the OS in manufacturing, in services, or a blending?

After a thorough literature research in important scientific databases (Scopus, Emerald Insight, Taylor \& Francis Online, Science Direct, among others) and focusing on papers published since the year 2000, we selected 38 papers addressing and focusing on OS issues in the context of manufacturing, services or PSS environments. In our analysis, we focus on the list of journals presented in Table I.

To the best of the author's knowledge there is no literature review covering OS in manufacturing, services and PSS. Our foremost contribution is filling this gap in the literature.

The paper is organized as follows. Section II provides an overview on the most important CPs, focusing both on classical
CPs and new trends. Section III stresses the implementation of OS in manufacturing companies, whilst Section IV focuses on the implementation of OS in purified service companies and Section V refers to the application of OS in PSS. Section VI provides an analysis on the proposed research questions and an analysis on the revised literature. We conclude the paper with a summary on the main findings of this research work.

\section{COMPETITIVE PRIORITIES AND OPERATIONS STRATEGY}

CPs and OS are closely linked [11]. CPs are a set of known goals for OS [29, 30]. In its turn, business strategy (BS) must be supported by OS decisions [30]. The definition of CPs encourages creating competitive edge for companies [31, 32]. Structural and infrastructural decisions influence the success or failure of organizations, concerning their established CPs [33]. If the objectives of a firm are not clearly translated into an adequate bundle of actions, its performance might not fulfil expectations [34].

CPs are particularly important for organizations due to reduced products life cycle and profits, and augmented delivery requirements and globalized competition [35]. Every company deals with more than one customer and should be able to adapt its OS. High flexibility and variety are, thus, crucial [27].

Cost, quality, flexibility, dependability and delivery are the most common CPs [27, 30, 34]. Others include innovation, environmental protection, social sustainability and customer service or after sales service [23, 32, 36, 37]. The innovation perspective makes the firm more disposed to recognize shifts in

TABLE I. LIST OF JOURNALS AND THE NUMBER OF ANALYZED PAPERS IN EACH

\begin{tabular}{|c|c|c|c|c|}
\hline \multirow{2}{*}{ Journal } & Papers & OS in Manufacturing & OS in Services & OS in PSS \\
\hline & No. of papers & No. of papers & No. of papers & No. of papers \\
\hline Computers \& Operations Research & 1 & 0 & 1 & 0 \\
\hline European Management Journal & 1 & 0 & 1 & 0 \\
\hline Industrial Marketing Management & 1 & 0 & 0 & 1 \\
\hline International Journal of Industrial Engineering & 1 & 0 & 1 & 0 \\
\hline International Journal of Operations \& Production Management & 7 & 3 & 1 & 3 \\
\hline International Journal of Production Economics & 4 & 2 & 2 & 0 \\
\hline International Journal of Production Research & 3 & 3 & 0 & 0 \\
\hline International Journal of Service Industry Management & 3 & 0 & 1 & 2 \\
\hline Journal of Business \& Industrial Marketing & 1 & 0 & 0 & 1 \\
\hline Journal of Engineering and Technology Management & 1 & 0 & 0 & 1 \\
\hline Journal of Industrial Engineering and Management & 1 & 1 & 0 & 0 \\
\hline Journal of Manufacturing Technology Management & 5 & 3 & 0 & 2 \\
\hline Journal of Operations Management & 4 & 3 & 1 & 0 \\
\hline Journal of Service Management & 1 & 0 & 0 & 1 \\
\hline Management Decision & 1 & 0 & 1 & 0 \\
\hline Managing Service Quality: An International Journal & 1 & 0 & 1 & 0 \\
\hline Procedia Social and Behavioral Sciences & 1 & 0 & 1 & 0 \\
\hline Technovation & 1 & 0 & 0 & 1 \\
\hline TOTAL & 38 & 15 & 11 & 12 \\
\hline
\end{tabular}


market dynamism and also to align its processes according to changes in industry [38, 39]. Environmental protection is supported by environmental programs, as ISO 14001 [40]. Based on this, we propose a division between CPs into classical and recent trends, as Fig. 2 illustrates.

Martín-Peña et al. [23] found, that there were three OSs: the first aimed at costs, the second was providing the product to the customer as quickly as possible and on time, with high quality, and the third was related to firms using new technologies and processes, allowing them to adapt to new customer requests. OS must adapt to new technologies and industry growth [39]. It is concluded that operations are designed to meet customers' needs and provide a competitive edge to the organizations.

The importance given to CPs was not the same throughout time. It has evolved from cost to quality and delivery and flexibility, being nowadays more focused on innovation and customer service [32]. Also, products are not only valued by functionality, but also by the brand $[9,26]$, that makes a statement about a living style and a positioning in society [26].

Considering the literature in OS and in CPs, we are now in position to summarize concepts in a generic framework. Our framework builds on the directed and emergent strategies concepts [25] and also on the top-down, bottom-up, market view and resources view, as in [3]. In our understanding the top-down perspective is a business needs perspective showing what the organization wants to do and how it is positioned in the market, the business plans. The market view is the market needs that show what the markets require the organization to provide. These two, business needs and market needs are the direct strategy. Meanwhile, the bottom-up perspective is related to the operations environment and provides knowledge that is built inside an organization, based on the operations experience. The resources view is related to the resources and capabilities owned by the organization, which dictate what the organization can and cannot do. These last perspectives, operations environment and resources and capabilities, are the emergent strategies. These concepts are summarized in Fig.3.

\section{OPERATIONS STRATEGY IN MANUFACTURING}

Manufacturing firms have been implementing different strategies, as just-in-time, agile manufacturing, quick response manufacturing, among others [11].

The fit between process environment and advanced manufacturing technology, and the impact on manufacturing and business performance were studied by Das and

\begin{tabular}{|c|c|}
\hline $\begin{array}{c}\text { Classical competitive } \\
\text { priorities }\end{array}$ & $\begin{array}{l}\text { Recent trends in } \\
\text { competitive priorities }\end{array}$ \\
\hline $\begin{array}{l}\text { - } \text { Cost; } \\
\text { - Quality; } \\
\text { - Flexibility; } \\
\text { - Dependability; } \\
\text { - Delivery. }\end{array}$ & $\begin{array}{l}\text { - Innovation; } \\
\text { - Environmental } \\
\text { protection; } \\
\text { - Social Sustainability; } \\
\text { - Customer/after sales } \\
\text { - service; } \\
\text { - Brand. }\end{array}$ \\
\hline
\end{tabular}

Fig. 2. Classical and recent trends in CPs.

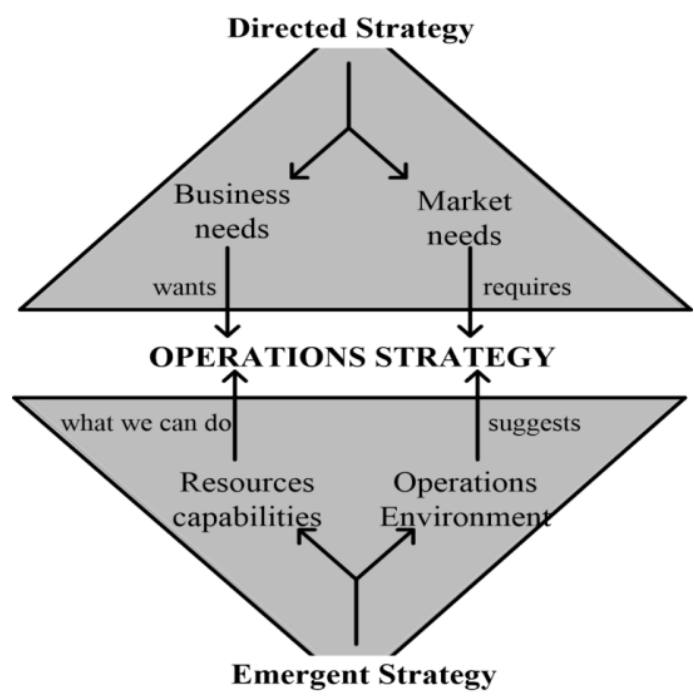

Fig. 3. Summary framework.

Narasimhan [41]. The manufacturing process the company chose was a strategic decision and impacted the overall performance. The proposed framework involved relationships amid process environment, manufacturing technology and performance. It put forward that the process environment configured investments in technology resources, infrastructures and human resources. The 'ideal profiles', which matched OS with competitive conditions, aligned the process environment with investments in manufacturing technology. A linkage between performance and technology investments was found.

Silveira [42] tested the use of the order-winners framework from Hill (1985), in 183 organizations from 17 countries. The author tested for a negative connection between performance in business and nonconformity with markets and products, and manufacturing and investments. Internal and external fits were considered. The manufacturing organizations replied to questionnaires and rated the order-winners variables (delivery speed, unique design and cost). The investment in plant and equipment, the production process and the number of days spent in work-in-process inventories were accessed. The business performance of the respondents was evaluated for the domestic market share, the return on investment (ROI) and the return on sales (ROS). Calculating the fit, the author concluded on a negative impact on market share for organizations with nonconformist products with markets and manufacturing and investment. This misfit was not so linked to ROI and ROS.

Using a sample of 353 Spanish manufacturing companies, in [33] were studied both choices and practices involved in operations strategies among manufacturing firms and their effects in the competitiveness of the organizations. To gather data, the researchers sent questionnaires to the firms. The main results showed that the most important structural decisions were related to size and plant capacity, followed by process, technology and environment protection. Among infrastructural decisions, the most important related to quality management, work force and manufacturing planning and control systems. The proper decisions provide a competitive edge to the firms. 


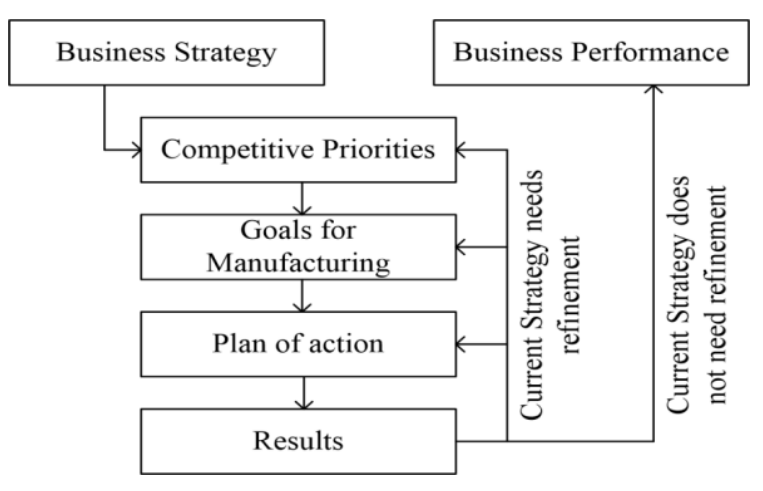

Fig. 4. Process formation for OS (adapted from [19])

In [43], Karlsson and Sköld added a network perspective to understand manufacturing management and strategy. The authors suggested that a framework with horizontal and vertical technologies to recognize the future manufacturing strategy would be beneficial. The horizontal technologies related to the performance characteristics of a product; and the vertical technologies were those integrated in technology disciplines (as in university departments). The horizontal technologies created customer value, using the vertical technologies. In the network perspective, different parts controlled distinct resources and activities without overlap. The network became the management unit, instead of the single organization.

Sarmiento, Knowles and Byrne [44] proposed a method for measuring consensus on manufacturing CPs. The authors proposed including the measurement on the importance of each $\mathrm{CP}$, and a measurement on potential relationships amongst pairs of CPs. This would help understanding the relationships between CPs from the strategic and operational perspectives. It was achieved a measure on the trade-offs amid CPs, which implied that knowledge about compatibility amongst CPs.

The 'plug and play' framework was proposed by Tan and Platts [45], as a tool for assisting managers in the process of building models for operations objectives and their adaptation. The authors stressed the need to provide a modelling tool for managers, that would easily and rapidly allow building a model for manufacturing simulation and analysis. The 'plug and play' framework used four building blocks (cost, quality, flexibility and throughput) that helped developing a manufacturing decision model, analyse connections and prioritising actions.

To examine the influence of BS upon the relationship between OS and business results, Oltra and Flor [30] used a sample of 76 Spanish ceramic tile firms. To represent the OS, the authors used the CPs and the BS following Miles and Snow's typology (1978). It was suggested that the effect OS had on business performance depended upon the type of strategy followed and, for this, there must be coherence between OS and BS.

A model creating alignment between business and operations strategies was provided by Shavarini, Salimian, Nazemi and Alborzi [22]. A sample of 160 Iranian companies was investigated by means of interviews and closed questionnaires. For the OS, the model considered top-down and resource-based approaches. The framework integrated BS,
CPs and the strategies in operational decisions. BS regulated OS and in opposite direction, operational capabilities regulated BS. After data handling, the authors concluded that the alignment differed between companies that achieved success and those that did not, and that different business strategies should be linked to different decisions in OS to seek for success.

$\mathrm{Xu}$, Zhang and Ma [46] introduced a framework for manufacturing OS and tested in 688 Chinese companies. The framework included the relationship among customer demand, enterprise strategy and manufacturing systems functional objectives. Customer demand was assumed to have positive effect on the competitive strategy (operational, financial and strategic); customer demand and competitive strategy were assumed to have a positive effect on the manufacturing systems functional objectives (efficiency, service, environment, time, quality, cost). The results from the questionnaires confirmed that customer demand had a positive effect both on competitive strategy and manufacturing systems functional objective. Also, customer demand had higher influence on the manufacturing systems functional objective than the competitive strategy.

According to Kim, Sting and Loch [19], the process formation of OS is complex and transversal to several layers of an organization. The authors presented a model for OS, based on Kim and Arnold's framework (1996), using integrated topdown and bottom-up perspectives. The model is presented in Fig. 4 (adapted). Using a sample of 111 action plans collected from six German manufacturing plants, the authors concluded that instead of competing with each other, top-down and bottom-up perspectives were complementary. Top-down action reflected the CPs, objectives and action plans, whilst bottom-up perspective emerged from operational uses and processes.

Using a sample of 1438 manufacturing plants, Singh, Wiengarten, Nand and Betts [47] studied which models could show how organizations use their operations capabilities (e.g. cost, quality, delivery). Two models were used through time to explain these capabilities use: the trade-off and the cumulative capabilities models. Still, the authors found other explanative models. These included the threshold model, in which OS achieved excellence in a core capability and threshold levels for others; the average model, reflecting that OS should achieve reasonable levels in all capabilities; the noncompetitive model, aiming at OS achieving below reasonable levels in all capabilities; and the multiple model, in which the OS did not contemplate a capability pattern. The findings of this work showed that the trade-off model was not used in the real manufacturing environment.

Sustainable competitive advantage can be developed by intersecting $\mathrm{OM}$ and the resource-based view, as in [48]. The authors used 18 high-technology Finnish manufacturing industries for the study and analysis of models for determining competitive performance. The resource-based view was able to support operations and also the need to revise and adjust the alignment between the manufacturing strategy and the resource allocation to maintain competitive advantage.

In a study about the apparel manufacturing industry in Sri Lanka, Jagoda and Kiridena [49] used a sample of 109 firms to study the factors influencing the existence of a given OS in a 
firm and the different outlines of OS and its relationship with internal and external environments and performance. It was settled that alternative configurations for OS existed and all could have good performance in distinct levels of competition. Also, it was found that OS did not always follow an official protocol; rather there were forced and evolutionary modes of OS, depending on external factors and strategic capabilities.

To evaluate the incorporation of environmental and social sustainability in OS, Longoni and Cagliano [37], assessed the fitness of these CPs with BS and their effectiveness in the assembly industry. It was proposed that integrating these priorities was not creating new OS, but complementing existing ones. Further the authors claimed that these CPs complemented more the OS that were market-oriented and capability-oriented and not so much the price-oriented. The performance of firms integrating environmental and social priorities in their strategy was better than for those that did not.

\section{OPERATIONS STRATEGY IN SERVICES}

The perspective of OS differs for manufacturing and services. It is complex to provide services in distinct cultural markets [50]. Different cultural markets have diverse expectations for services. Some companies move from one market to another with minimal changes in how they provide services, while others create an intimate relationship with their customers and assume different strategies for different markets. The paper stated that each cultural segment will be preferably attracted to service product attributes that are more related to their cultural environment. Nonetheless, when customers use a service with determined expectations (as getting foreign food), they expect nothing linked to their culture. Customization can be hard in multicultural markets and standardization can be a wise option. Organizations should be sensitive regarding this; as the metrics used in measuring service performance are intangible. Branding can be very important in services.

In [51], Kim, Kim and Kim explored the design of an OS framework for implementation in a Korean telecommunications organization. The decision making was made by using a Multi-Attribute Decision-Making analysis. The proposed framework was claimed to be a useful guideline to develop OS and to build a network management centre.

A framework for service strategy and an adaptation of manufacturing flexibility for application to services operations context were introduced by Aranda [52], and tested for Spanish consulting firms. The flexibility dimension in services addresses the need for the market introduction of new adjusted designs and services rapidly. The authors stressed the customer interaction and customization importance as demanding more flexibility from services. The direct effects of OS in financial performance were higher than the indirect effects of flexibility. Also, the direct effects of OS in non-financial performance were lower than the indirect effects through flexibility.

An alternative for service companies is to provide services through the web, as explored in [53]. The e-service is flexible and the contact between the service provider and the customer is performed through the ICT. The e-service can be restrictive concerning the viewing and hearing areas, however the customers are not constrained by distance and opening hours.
There were three groups of bases in e-service operations: services marketing, service design and service delivery. The first dealt with matching the market needs with the resources owned by the organization; the second included all assets related to facilities, servers and equipment; and the third related to the delivery of products to customers.

In [54], Kim et al. developed a framework for service quality analysis and improvement, and performed a case study in a telecommunications company in Asia. The authors used the quality function deployment for collection, organization and analysis of qualitative information; and structural equation modelling (SEM) to build and analyse quantitative models for strategy upgrading. The framework had four phases. First, the construction of the house of quality (HQ); followed the analysis of the data in the HQ. Then the strategy development for improvement of customer value added. Finally the SEM analysis for improvement of customer value added.

The study in [34], focused on 190 Australian service firms. It tracked a relationship between the CPs and the areas of operational activities. The authors proposed two research questions. The first aimed at finding if there was difference in the relationship between OS and operations activities in firms performing well and in those not performing well. The second research question was a consequence of the first: in case there were differences between low and high performing firms, which were those differences and what was their pattern. From this study, the authors found that there was different alignment between strategic priorities and operations activities when comparing firms with high and low performances. For companies competing in low cost, the technology activities were more important; meanwhile, for firms competing on delivery, the most important was the relationship between delivery and logistics and scheduling activities.

To develop an OS for IT sector in developing countries, Ibrahim [32] conducted a study in a telecommunications company in Egypt. The main goal was the identification of the differentiating CPs and the market segments. Quality was the most important operational strategy and customer focus and service provision were the most important variables in sales. For projects prioritizing cost, success was not notable. Still, it was suggested that the strategy formulation could be performed after-market testing, to allow a company to adjust its CPs to market segments. The theoretical framework included CPs directly affecting the successful sales and also the marketsegmentation, which indirectly influenced successful sales.

An university was used for a case study in [55], for strategy formulation in organizations. First the competitive factors were identified. Considering the organization capabilities, the areas where it was strong to compete were identified, and those competing areas where it should not compete. The SWOT analysis was used to formulate strategy. The final strategy formation used fuzzy screening technique.

In [56], were used two models of complexity theory in service innovation (Kauffman's NK model and organizational ambidexterity). The author proposed an evolutionary process for service innovation. There was a positive link amid service innovation success and the view the service provider had about service innovation as an evolutionary process. Another 
proposition was linked to the success of service innovation being related to small variations targeted for improving existing services. It was proposed that success in service innovation would be positively linked to major variation in finding new services. There was focus on the relevance of joint effort between service provider and customer. The success of service innovation would be attained to taking advantage of this interaction.

The service sector has more difficulty in reaching a good fit between competitive and operations strategies [21]. Lillis and Sweeney [21] studied the relationships between the view taken by the company (resource-based or market-based) for competitive strategy formulation and the strategic role adopted for operations. Furthermore, the authors used the information to understand how these relationships could improve the internal strategic fit. In the sample of firms that were used, it was found that most companies adopted a market-based view, being the organizations internally supportive of this view.

Silvestro [57] proposed the performance topology mapping to have better insight on performance drivers for developing OS and correctly manage operations in services. The author claimed that this new approach is more robust for building strategy maps, than existent methods in literature. There was a defence that the OS basis should be "empirically demonstrable performance", rather than managerial conventions. The map in the performance topology had links among performance variables to build a network of performance relationships.

\section{Operations StRATEgy IN PROdUCt-SERVICE SYSTEMS}

Nowadays manufacturing companies have shifted their orientation from only selling manufacturing-based products becoming more product-service oriented systems. Industries are keen to add services not only as "add-on" of their products but more as a bundle of total offering. This approach is called Product-Service System (PSS) where companies are offering an integrated products and services which emphasizes on value in use rather than ownership

Mathieu [58] proposed a typology for manufacturing companies wanting to integrate services in their offering. The typology included service specificity and organizational intensity. The first related to customer service, product service and service as a product; the second could be tactical, strategic or cultural. The author referred the variety of services that could be offered by manufacturing companies, depending if those companies were targeting a consumer market or a business-to-business (B2B) market. For the consumer market, the offering usually fell on distribution and repair; whereas, in B2B market, it was about the suppliers providing financing, after-sales and/or training services. Several benefits could arise from using a service strategy: financial, strategic, marketing, competitiveness, high value to customers and innovation.

In [59], Oliva and Kallenberg focused on the transition of manufacturing companies creating service organizations. The transitional process was linked to building capabilities and to finding a balanced relationship among the product end-users and the service offer. The authors focused on manufacturing firms transitioning from product providers to almost merely service providers, with the product raising minority concerns. In this transitional phase the concerns were related to changing goals, incentives, management, and others. Most organizations in the referred transition would, at very early stage, make a separation among the manufacturing and service operations.

Some products that can be found in the market have associated services. Following this, Kumar and Kumar [60], published about a conceptual framework to develop services in industrial systems and products. The authors referred the importance of service and product support in increasing customer satisfaction, loyalty, to create advertisement through customers spreading the good words about the firm and as a shield against low-cost competitors. The framework included aspects as product design features, customer's organizational culture and location. These aspects were considered the most relevant in service delivery strategy. The framework paid attention to customer requests in strategy building, which allowed organizations to shrink the gap between customer service delivery expectations and perceived service delivery.

Gebauer [61] studied the different service strategies to be included in manufacturing companies. There were four strategies in the study. These were related to after-sales service, concentrating in cost leadership and insuring proper functioning of the equipment; customer support, that invested in product and service differentiation; outsourcing partners, using cost leadership and service and product differentiation; and the development partners, that were related to research and development of services in order to make customers benefit from the developed competencies. The framework developed used a combined research on external environment and strategies. The metrics related to the external environment were competitive intensity in product and services, market growth, price and customer's choices. The strategies related to cost leadership, differentiation in products and services, the service offering and the marketing differentiation of services.

In 2009, Aurich, Wolf, Siener and Schweitzer [62] referred the crescent need customers had in having services associated to high-quality products. Hence, the authors proposed a framework with all the activities that were relevant for the configuration of PSS, using a case study to exemplify the activities presented in the framework. The proposed framework was divided in three element groups. The first was related to the basics: physical structure of the product, product life cycle and the structure of the services. The second analysed the influence of the product life cycle, as well as the impact of the service, using the data gathered from the first element group. The third represented the configuration of the PSS. The configuration regarded technical and service aspects. In the framework was established a continuous improvement of products, services, procedures and regulations.

Baines, Lightfoot, Peppard, Johnson, Tiwari and Shehab [63] presented a framework that could be used by manufacturing firms as a tool to product-services association. The fact that operations around products were connected to the materials transformation into goods was debated; services operations were about providing experiences to customers. Therefore, for product-centric servitisation, there should be a blending of extremes. The typical assembly of products and the 
test and repair near the customers, exist. Focus should be given to the response time and to reliability in the supply chain, because products should be readily available, and with an offering of very similar products, but with distinct supporting services. The employees should have knowledge on the product characteristics and being able to establish a reliable relationship with the customers.

Several challenges are experienced by manufacturing companies undergoing a servitisation process. This was highlighted in [64], where a single-case study was used to study the challenges faced by UK manufacturing firms that aimed at becoming product-service providers. The authors identified five categories of challenges faced by these firms: embedding product-service culture, providing an integrated offering, acquisition of capabilities to compete in services, strategic alignment, and development of supplier relationships, this is, good cooperation with the supporting network.

Another framework based on a literature review, for OS in PSS was proposed by Datta and Roy [65]. The aim of the work was to provide an aiding tool in the development of the product/service offering. The framework included four key dimensions. The first was the contract definition and included aspects as price, payment plan, technical and functional issues. The second dimension was the service provider OS, including the organisational readiness. The service delivery was related to ensuring that the service provision had a performance as specified by customers. Finally, there was the customer OS.

Olhager and Johansson [66] referred that products and services were likely to have distinct CPs. Hence, the authors provided a framework integrating manufacturing and services operations. It was considered important a joint analysis on both. The lead and chase strategies for manufacturing and services paid more attention to capacity availability and flexibility; the lag and level strategies focused on capacity use and cost efficiency. It was also a possibility that low cost operations would be desirable in manufacturing and the service demand would require excess capacity to have flexibility.

Santamaría, Nieto and Miles [67] studied the introduction of new improved services by manufacturing organizations. When manufacturing companies under servitisation process invested in human resources, they were investing in one of the critical roles in developing new skills for service innovation. Training activities were more relevant for service innovation and not so much for process innovation. Customer interaction was crucial in servitisation. R\&D was a factor with more impact in service innovation than in manufacturing.

To provide a guideline for managers interested in evolving from product to services industries, Gebauer, Ren, Valtakoski and Reynoso [68], made a review on services strategic assets in manufacturing and also discussed the impact of services in industry. The authors proposed a framework with focus on the value chain expansion. The firms direct operations towards provision of new services to correspond to market demand and to maintain a competitive edge and to grow financially.

There is a common interest in understanding the practices and technologies used in successful servitization. Baines and Lightfoot [69] developed a case study in manufacturing firms that gone over a successful servitisation to reveal the practices and technologies used. The authors found six technologies and practices to deliver advanced services: facilities and location, micro-vertical integration and relations with suppliers, information and communication technologies, human resources and their skills, performance measurement and value demonstration, and business practices and customer relations.

\section{DISCUSSION AND CONCLUSIONS}

This paper contributes to the existing OM literature exploring two main questions that have been missing in prior research studies. Drawing on literature addressing operations strategy, firstly we explore if there are any difference in OS in manufacturing and services organizations and what distinguishes them. Second, we explore where does the PSS in OS fall, namely does it approach more to the OS in manufacturing, in services, or a combination of both.

From the manufacturing perspective in OS, it was a common understanding that investments in technology, equipment, plant, process environment were very important decisions for OS [33, 41, 42]. The choice of the manufacturing technology was considered a very important strategic decision, from which business performance was dependable [33]. The existence of different 'technologies' was considered in literature [43]. These technologies were combined to attain unique product offer, creating customer value. Such studies relying on the manufacturing technology show that effective technological choices are important in OS in manufacturing. A correct investment in technology is a competitive tool.

The CPs were used to represent OS. Some authors proposed an analysis on the CPs as a combination, to better define strategy and operations, with a trade-off approach in the CPs [44]. Nonetheless, others identified the trade-off model concept as not being used by manufacturing companies in practice [47]. Other approach used the CPs as building blocks for developing a tool to aid managers in decision making and monitoring the evolution of the strategic decisions [45]. This indicates that CPs could effectively be used to represent OS.

A link among studies in manufacturing organizations was the prominent need to correctly connect the OS formulation with the CPs and BS, to provide competitive advantage and increased market share for firms. In [22, 30], was stressed the need to align OS and BS. Customer demand was found very important for competitive and manufacturing strategies [46].

There was no agreement on the best perspective for OS. In [22] were adopted top-down and resource-based perspectives; and in [48], a purified resource-based view. In [19], a complementarity of top-down and bottom-up perspectives was found beneficial. Building on literature, we believe the development context of OS dictates the best approach.

OS does not always follow strict official protocols. It is rather more adaptive, depending on external factors and on strategic capabilities [49]. For example, more recently, social and environmental concerns were found to be very important for manufacturing organizations pursuing competitive edge, by complementing existent OS, rather than creating new OS [37]. 
Considering the above paragraphs, there seems to be a time evolution on the important assets in OS. First, technology appeared to be the focus of research. Followed the highlight on the CPs to better describe and translate OS. Then, the focus was on the alignment of CPs, OS and BS. The perspective on OS goes from a top-down approach to a blending of top-down and bottom-up perspectives. Finally appeared new CPs concerned with the environment and society to redefine current OS and the notion that the OS plan is not a static, but an everchanging reality. Even though this outline appears strong, we acknowledge that this evolutionary conclusion might not be completely accurate due to the reduced number of papers reviewed and their limited time frame.

Regarding OS in services, three of the analysed papers included the operations perspective in telecommunications firms [32, 51, 54]. In [51] was introduced a framework for development of OS, which indicates that in services, there is also the need to have good planning of the operations actions. Furthermore, improvement in telecommunications services was a focus; it meant to increase the customer value added [54]. A great focus on the service quality was given in [32, 54]. In [54] was given a tool for service quality analysis and improvement, whilst in [32], quality was found to be the most important CP.

In fact, the strategy formulation in service was pointed as decisions to be tailored after a market assessment [32]. This leads to a finding in another of the analysed paper, [55], that points to the importance of organizations to clearly define their strengths and weaknesses to identify the areas where they should be competing or not. Moreover, manufacturing concepts as flexibility were adapted to fit the services context [52]. Another issue referred in the services literature was the difficulty in adapting a service to distinct cultural markets [50].

The service sector finds more difficulties in reaching a good fit between competitive and operations strategies [21] and service providers tend to focus more on a market-based view. The alignment between strategic and operations priorities is highlighted [34] There is also the need to provide innovative services to the markets, perhaps even through the web [53].

Comparing OS in manufacturing and in services, some commonalties can be found. For both, it is important to find an alignment between the strategic activities and the target market. Services and manufacturing organizations should clearly define in which priorities the organization aims at competing. Also, the OS was pointed not to be adaptive to external factors.

Several differences can be observed. In services, a great focus is given to quality; meanwhile, for manufacturing, the focus does not fall into a single CP, but rather a set of CPs. The difficulty in adapting a service to distinct market segments is common; also, assessing a service performance is harder than measuring the performance in manufacturing environment. In services, companies tend to focus more on the market view, which is not the same as in manufacturing, where there is an understanding that different views can be successful, depending on the business context. Even though technology was also referred in the services literature, a much higher importance was given to technology in the manufacturing literature. The environmental and social matters were given more importance in the manufacturing literature.
The above two paragraphs answer to our first research question. There are several differences among the implementation of OS in manufacturing and services that indicate the higher difficulty in evaluating services. Some commonalties were also found. This leads us to the conclusion that it is difficult to clearly distinguish all the characteristics differentiating strategic practices for manufacturing and services organizations. The best practices always depend on the competitive context and, at times, what is applied to manufacturing can be applied to services and vice-versa.

In PSS, the association of services to products has been pointed to increase customer satisfaction and loyalty [60], innovativeness and competitiveness [58]. Some challenges were identified for firms switching from product providers to providers of coupled product-service. The integration of a services culture in manufacturing environment is not straightforward [64], and often, companies early separate between manufacturing and services operations [59].

Several frameworks in PSS were identified [60, 62, 63, 65]. Albeit conceptually different, all combined product and services features and customer relationships. Therefore, the blending of product and service, and their orientation towards customers is what characterizes PSS frameworks.

Product-service providers can compete in dimensions, as cost, product or service differentiation [61]. Indeed, products and services were pointed to have distinct CPs [66]. Hence, there should be a joint analysis on products and services, since a blending of operations characteristics of both needs to be considered to undergo successful servitisation process.

Human resources and R\&D funds were considered critical in a correct product-service provision. $R \& D$ was more critical for services innovation than for product innovation [67].

Considering the above, we now face research question number two. Following the line of thought in the paper [63], we believe that OS in PSS results from a blending of strategies adopted for manufacturing and for services. A high focus in customer and in human resources is crucial for PSS, which is similar to what happens in service provision. Also a good alignment with suppliers and the cost efficiency advantage acquired for the correct processing choice in manufacturing organizations, appear as critical assets in PSS. A summary of the main findings of this paper and the challenges of the area can be found in Table II.

This study contributes to both the OM and strategy literature streams. We provide two major contributions to the existent literature. First, we analysed the differences in OS in manufacturing and services organizations. This led us to concluding that the diving line between manufacturing and services can be blurred, even though several differences were found. Concerning to the PSS, in the line of previous publications, we believe that OS frameworks follow a blending of the strategy adopted in manufacturing and in services.

\section{ACKNOWLEDGMENT}

This work was financed by the Project "NORTE-07-0124FEDER-000057”, financed by the North Portugal Regional 
TABLE II. SUMMARY OF FINDINGS AND THE CHALLENGES OF THE AREA

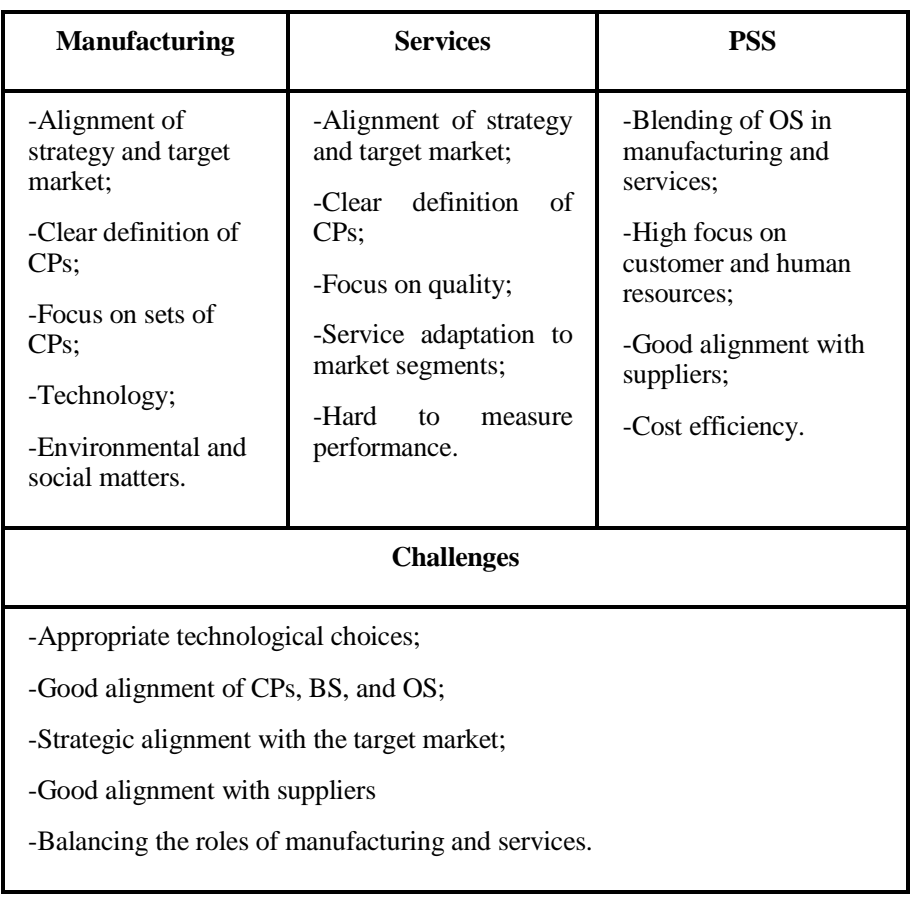

Operational Programme (ON.2 - O Novo Norte), under the NSRF, through the European Regional Development Fund, and by national funds, through the Portuguese funding agency, FCT - Fundação para a Ciência e a Tecnologia.

\section{REFERENCES}

[1] W. Skinner, "Manufacturing-Missing Link in Corporate Strategy," Harvard Business Review, vol. 47, pp. 136-145, 1969.

[2] R. H. Lowson, "Retail operational strategies in complex supply chains," International Journal of Logistics Management, vol. 12, pp. 97-111, 2001.

[3] N. Slack and M. Lewis, Operations Strategy, 3rd ed. England: Prentice Hall, 2011.

[4] J. A. V. Mieghem, "Operations Strategy: Concept and Framework," in Operations Strategy: Principles and Practice, ed, 2008.

[5] R. D. Reid and N. R. Sanders, Operations Management: An integrated approach, 4th ed. United States of America: George Hoffman, 2011.

[6] N. G. Rytter, H. Boer, and C. Koch, "Conceptualizing operations strategy processes," International Journal of Operations \& Production Management, vol. 27, pp. 1093 - 1114, 2007.

[7] A. S. Khalifa, "The "strategy frame" and the four Es of strategy drivers," Management Decision, vol. 46, pp. 894 - 917, 2008.

[8] M. E. Porter, "Towards a dynamic theory of strategy," Strategic Management Journal, vol. 12, pp. 95-1 I7, 1991.

[9] A. Enders, A. König, H. Hungenberg, and T. Engelbertz, "Towards an integrated perspective of strategy," Journal of Strategy and Management, vol. 2, pp. 76 - 96, 2009.

[10] R. Feurer and K. Chaharbaghi, "Strategy formulation: a learning methodology," Benchmarking for Quality Management \& Technology, vol. 2, pp. 38 - 55, 1995 .

[11] [11] A. Gunasekaran and E. W. T. Ngai, "The future of operations management: An outlook and analysis," International Journal of Production Economics, vol. 135, pp. 687-701, 2012.

[12] E. P. d. Lima, S. E. G. d. Costa, and A. R. d. Faria, "Taking operations strategy into practice: Developing a process for defining priorities and performance measures," Int. J. Production Economics, vol. 122, pp. 403-418, 2009
[13] L. Nielsen-Englyst, "Operations strategy formation - a continuous process," Integrated Manufacturing Systems, vol. 14, pp. 677 - 685, 2003

[14] E. D. Adamides, "Linking operations strategy to the corporate strategy process: a practice perspective," Business Process Management Journal, vol. 21,2015 .

[15] E. L. Paiva, A. V. Roth, and J. E. Fensterseifer, "Organizational knowledge and the manufacturing strategy process: A resource-based view analysis," Journal of Operations Management, vol. 26, pp. 115132, 2008.

[16] S. Brown, B. Squire, and M. Lewis, "The impact of inclusive and fragmented operations strategy processes on operational performance," International Journal of Production Research, vol. 48, pp. 4179-4198, 2010

[17] P. Ward, J. McCreery, and G. Anand, "Business strategies and manufacturing decisions: an empirical examination of linkages," International Journal of Operations \& Production Management, vol. 27, pp. 951-973, 2007.

[18] P. Nath, S. Nachiappan, and R. Ramanathan, "The impact of marketing capability, operations capability and diversification strategy on performance: A resource-based view," Industrial Marketing Management, vol. 39, pp. 317-329, 2010.

[19] Y. H. Kim, F. J. Sting, and C. H. Loch, "Top-down, bottom-up, or both? Toward an integrative perspective on operations strategy formation," Journal of Operations Management, vol. 32, pp. 462-474, 2014.

[20] R. McIvor, "How the transaction cost and resource-based theories of the firm inform outsourcing evaluation," Journal of Operations Management, vol. 27, pp. 45-63, 2009.

[21] B. Lillis and M. Sweeney, "Managing the fit between the views of competitive strategy and the strategic role of service operations," European Management Journal, vol. 31, pp. 564- 590, 2013.

[22] S. K. Shavarini, H. Salimian, J. Nazemi, and M. Alborzi, "Operations strategy and business strategy alignment model (case of Iranian industries)," International Journal of Operations \& Production Management, vol. 33, 2013.

[23] M. L. Martín-Peña and E. Díaz-Garrido, "Typologies and taxonomies of operations strategy: a literature review," Management Research News, vol. 31, pp. $200-218,2008$

[24] R. H. Hayes and S. C. Wheelwright, Restoring Our Competitive Edge: Competing through Manufacturing. New York, 1984

[25] M. Iansiti, Operations Strategy: Harvard Business Publishing, 2013.

[26] R. H. Lowson, "Operations strategy: genealogy, classification and anatomy," International Journal of Operations \& Production Management, vol. 22, pp. 1112 - 1129, 2002.

[27] R. H. Lowson, "The nature of an operations strategy: combining strategic decisions from the resource-based and market-driven viewpoints," Management Decision, vol. 41, pp. 538-549, 2003.

[28] D. Barnes, "Research methods for the empirical investigation of the process of formation of operations strategy," International Journal of Operations \& Production Management, vol. 21, pp. 1076 -1095, 2001.

[29] M. J. Oltra, C. Maroto, and B. Segura, "Operations strategy configurations in project process firms," International Journal of Operations \& Production Management, vol. 25, pp. 429 - 448, 2005.

[30] M. J. Oltra and M. L. Flor, "The moderating effect of business strategy on the relationship between operations strategy and firms' results," International Journal of Operations \& Production Management, vol. 30 , pp. $612-638,2010$

[31] T. J. Moran and P. Meso, "A Resource Based View Of Manufacturing Strategy And Implications To Organizational Culture And Human Resources," Journal of Business \& Economics Research, vol. 6, pp. 99 110, 2008.

[32] S. E. Ibrahim, "An alternative methodology for formulating an operations strategy: the case of BTC-Egypt," Management Decision, vol. 48, pp. 868 - 893, 2010

[33] E. D. Garrido, M. L. Martín-Peña, and F. García-Muiña, "Structural and infrastructural practices as elements of content operations strategy. The effect on a firm's competitiveness," International Journal of Production Research, vol. 45, pp. 2119-2140, 2007. 
[34] D. I. Prajogo and C. M. McDermott, "The relationships between operations strategies and operations activities in service context," International Journal of Service Industry Management, vol. 19, pp. 506 $520,2008$.

[35] K. Naesens, L. Gelders, and L. Pintelon, "A swift response framework for measuring the strategic fit for a horizontal collaborative initiative," Internatonal Journal of Production Economics, vol. 121, pp. 550-561, 2009.

[36] C. Sung-Eui, "Developing new frameworks for operations strategy and service system design in electronic commerce," International Journal of Service Industry Management, vol. 16, pp. 294 - 314, 2005.

[37] A. Longoni and R. Cagliano, "Environmental and social sustainability priorities," International Journal of Operations \& Production Management, vol. 35, pp. 216 - 245, 2015.

[38] J. A. Siguaw, P. M. Simpson, and C. A. Enz, "Conceptualizing Innovation Orientation: A Framework for Study and Integration of Innovation Research," The Journal of Product Innovation Management, vol. 23, pp. 556-574, 2006.

[39] A. Nair and W. R. Boulton, "Innovation-oriented operations strategy typology and stage-based model," International Journal of Operations \& Production Management, vol. 28, pp. 748 - 771, 2008.

[40] A. Galeazzo, A. Furlan, and A. Vinelli, "Understanding environmentaloperations integration: The case of pollution prevention projects," International Journal of Production Economics, vol. 153, pp. 149-160, 2014

[41] A. Das and R. Narasimhan, "Process-technology fit and its implications for manufacturing performance," Journal of Operations Management, vol. 19, pp. 521-540, 2001.

[42] G. J. C. d. Silveira, "Market priorities, manufacturing configuration, and business performance: an empirical analysis of the order-winners framework," Journal of Operations Management, vol. 23, pp. 662-675, 2005 .

[43] C. Karlsson and M. Sköld, "The manufacturing extraprise: an emerging production network paradigm," Journal of Manufacturing Technology Management, vol. 18, pp. 912 - 932, 2007.

[44] R. Sarmiento, G. Knowles, and M. Byrne, "Strategic consensus on manufacturing competitive priorities: A new methodology and proposals for research," Journal of Manufacturing Technology Management, vol. 19, pp. $830-843,2008$

[45] K. H. Tan and K. Platts, "Linking operations objectives to actions: A plug and play approach," International Journal of Production Economics, vol. 121 , pp. 610-619, 2009.

[46] W. Xu, Q. Zhang, and J. Ma, "The relationship among customer demand, competitive strategy and manufacturing system functional objectives," Journal of Industrial Engineering and Management vol. 6, pp. 1238-1254, 2013.

[47] P. J. Singh, F. Wiengarten, A. A. Nand, and T. Betts, "Beyond the tradeoff and cumulative capabilities models: alternative models of operations strategy," International Journal of Production Research, 2014.

[48] Y. Liu and L. Liang, "Evaluating and developing resource-based operations strategy for competitive advantage: an exploratory study of Finnish high-tech manufacturing industries," International Journal of Production Research, vol. 53, pp. 1019-1037, 2015.

[49] K. Jagoda and S. Kiridena, "Operations strategy processes and performance," Journal of Manufacturing Technology Management, vol. 26, pp. $261-279,2015$.

[50] M. E. Pullman, R. Verma, and J. C. Goodale, "Service design and operations strategy formulation in multicultural markets," Journal of Operations Management, vol. 19, pp. 239-254, 2001

[51] Y.-M. Kim, J.-H. Kim, and S.-H. Kim, "Use of multi-attribute decision analysis for designing operations system framework in telecommunications management network," Computers \& Operations Research, vol. 27, p. 1375\}1388, 2000.
[52] D. A. Aranda, "Service operations strategy, flexibility and performance in engineering consulting firms," International Journal of Operations \& Production Management, vol. 23, pp. 1401-1421, 2003.

[53] H. Surjadjaja, S. Ghosh, and J. Antony, "Determining and assessing the determinants of e.service operations," Managing Service Quality: An International Journal, vol. 13, pp. 39-53, 2003.

[54] K.-J. Kim, H.-W. Cho, I.-J. Jeong, J.-C. Park, Y.-J. Park, C.-G. Kim, et al., "Service quality analysis and improvement: development of a systematic framework," International Journal of Industrial Engineering, vol. 13, pp. 177-187, 2006.

[55] N. Manteghi and A. Zohrabi, "A proposed comprehensive framework for formulating strategy: a Hybrid of balanced scorecard, SWOT analysis, Porter's generic strategies and Fuzzy quality function deployment," Procedia Social and Behavioral Sciences, vol. 15, pp. 2068-2073, 2011

[56] B. K. Chae, "An evolutionary framework for service innovation: Insights of complexity theory for service science," International Journal of Production Economics, vol. 135, pp. 813-822, 2012.

[57] R. Silvestro, "Performance topology mapping: understanding the drivers of performance," vol. 156, pp. 269-282, 2014.

[58] V. Mathieu, "Service strategies within the manufacturing sector: benefits, costs and partnership," International Journal of Service Industry Management, vol. 12, pp. 451 - 475, 2001

[59] R. Oliva and R. Kallenberg, "Managing the transition from products to services," International Journal of Service Industry Management, vol. 14, pp. 160 - 172, 2003.

[60] R. Kumar and U. Kumar, "A conceptual framework for the development of a service delivery strategy for industrial systems and products," Journal of Business \& Industrial Marketing, vol. 19, pp. 310 - 319, 2004.

[61] H. Gebauer, "Identifying service strategies in product manufacturing companies by exploring environment-strategy configurations," Industrial Marketing Management, vol. 37, pp. 278-291, 2008.

[62] J. C. Aurich, N. Wolf, M. Siener, and E. Schweitzer, "Configuration of product-service systems," Journal of Manufacturing Technology Management, vol. 20, pp. 591 - 605, 2009.

[63] T. Baines, H. Lightfoot, J. Peppard, M. Johnson, A. Tiwari, E. Shehab, et al., "Towards an operations strategy for product-centric servitization," International Journal of Operations \& Production Management, vol. 29, pp. 494 - 519, 2009

[64] V. Martinez, M. Bastl, J. Kingston, and S. Evans, "Challenges in transforming manufacturing organisations into product-service providers," Journal of Manufacturing Technology Management Decision, vol. 21, pp. 449 - 469, 2010.

[65] P. P. Datta and R. Roy, "Operations strategy for the effective delivery of integrated industrial product-service offerings: Two exploratory defence industry case studies," International Journal of Operations \& Production Management, vol. 31, pp. 579 - 603, 2011

[66] J. Olhager and P. Johansson, "Linking long-term capacity management for manufacturing and service operations," Journal of Engineering and Technology Management, vol. 29, pp. 22-33, 2012.

[67] L. Santamaría, M. J. Nieto, and I. Miles, "Service innovation in manufacturing firms: Evidence from Spain," Technovation, vol. 32, pp. $144-155,2012$

[68] H. Gebauer, G.-J. Ren, A. Valtakoski, and J. Reynoso, "Service-driven manufacturing: Provision, evolution and financial impact of services in industrial firms," Journal of Service Management, vol. 23, pp. 120 - 136, 2012

[69] T. Baines and H. W. Lightfoot, "Servitization of the manufacturing firm: Exploring the operations practices and technologies that deliver advanced services," International Journal of Operations \& Production Management, vol. 34, pp. 2 - 35, 2013. 